\title{
Study on safety of non-descent vaginal hysterectomy for enlarged uterine size for benign uterine pathologies
}

\author{
Neelam Manda ${ }^{1 *}$, Oby Nagar' ${ }^{1}$, Lata Rajoria ${ }^{1}$, C. P. Dadhich ${ }^{2}$
}

\begin{abstract}
${ }^{1}$ Department of Obstetrics and Gynecology, SMS Medical College, Jaipur, Rajasthan, India
${ }^{2}$ Department of Obstetrics and Gynaecology, Eternal Hospital, Jaipur, Rajasthan, India
\end{abstract}

Received: 27 January 2019

Accepted: 05 March 2019

\author{
*Correspondence: \\ Dr. Neelam Manda, \\ E-mail: mandaneelam@gmail.com
}

Copyright: (c) the author(s), publisher and licensee Medip Academy. This is an open-access article distributed under the terms of the Creative Commons Attribution Non-Commercial License, which permits unrestricted non-commercial use, distribution, and reproduction in any medium, provided the original work is properly cited.

\begin{abstract}
Background: Vaginal hysterectomy is less commonly performed for benign pathologies if the uterine size exceeds 12 weeks in the belief that complications could be higher in this group. The aim of this prospective study was to compare surgical outcomes and safety of vaginal hysterectomy in women with non-prolapsed uteri of $>12$ weeks size to those with uteri of $<12$ weeks removed vaginally for similar indications.

Methods: In this prospective cohort study, 92 patients were included who underwent NDVH for benign uterine conditions between May 2016 to December 2018. The index group comprised 32 women who underwent vaginal hysterectomy for non-prolapse uterus with uterine enlargement ( $>12$ weeks), while the control group consisted of 60 women with uteri $<12$ weeks. Demographic data, duration of surgery, blood loss, intraoperative and postoperative complications were compared.

Results: Women in the two groups had statistically similar mean age, Body Mass Index and parity (44 vs 42.77 years, 20.8 vs $21.56 \mathrm{~kg} \mathrm{~m}^{3}$ and 3.26 vs 3.83 , respectively; $\left.p>0.05\right)$. The mean operative time was significantly longer in the index group (62.47min; vs $48.17 \mathrm{~min}$; $\mathrm{p}<0.0001)$. Women with enlarged uteri had greater mean estimated blood loss (123.2 ml vs $75.9 \mathrm{ml} ; \mathrm{p}<0.0001)$ but the mean length of hospital stay was similar (5.531 days vs 5.177 days; $\mathrm{p}>$ 0.05). Intra- and post-operative complications such as blood transfusion and pelvic sepsis, post-operative febrile illness and systemic infections were comparable in both groups.

Conclusions: Vaginal hysterectomy in larger non-prolapsed uteri takes longer to perform and is associated with more blood loss compared to uteri $<12$ weeks but is not associated with a significant increase in complication rates.
\end{abstract}

Keywords: Enlarged uterus, Non-prolapsed, Vaginal hysterectomy

\section{INTRODUCTION}

Hysterectomy is common operation performed for benign uterine conditions and can be done through abdominal, vaginal and laparoscopic routes. ${ }^{1,2}$ Traditional abdominal and vaginal hysterectomies represent the most and least invasive techniques respectively. ${ }^{3-5}$ The ease and convenience offered by a large abdominal incision have led to the preponderance of abdominal hysterectomy over the vaginal route for NDVH. ${ }^{6,7}$ However, $\mathrm{AH}$ as the most invasive procedure, and is associated with abdominal trauma, intraoperative and postoperative complications, and slow postoperative recovery. ${ }^{6,7}$ Compared with traditional open gynaecological surgeries, VH provides less postoperative pain, more rapid recovery, and shorter hospital stay. ${ }^{7-9}$ The common belief that large sized uteri, endometriosis, Pelvic inflammatory disease, previous surgeries, and narrow vagina make vaginal route difficult, are not considered to be contra-indications for nondescent vaginal hysterectomy anymore and can be successfully attempted in all these conditions. ${ }^{10-12}$ It has a clear advantage over the abdominal route in obese 
women. Lack of expertise and the curve in learning the technique also has major impact on the number of procedures performed. ${ }^{10,13}$ Surgical haemostasis can be secured by a variety of methods, including mechanical (sutures) or vessel coagulation (diathermy), although electrocoagulation diathermy has been shown to be unreliable for vessels larger than $2 \mathrm{~mm}$ in diameter. ${ }^{14-16}$ Electrosurgical vessel sealing is a new haemostatic system based on the combination of pressure and bipolar electrical energy, and is able to seal vessels up to $7 \mathrm{~mm}$ in diameter. This sealing system has been used in $\mathrm{VH}$ with encouraging results and causes further reduction in operative time and blood loss. ${ }^{17-20}$ When the uterine size exceeds 12 weeks, vaginal approach is avoided in the belief that surgical complications could be higher in this group compared to smaller uteri but studies showed VH in large sized uterus can be done by various methods of debulking. ${ }^{21,22}$ There are few studies available on vaginal hysterectomy for benign pathologies with uterine size $>12$ weeks. Observational and comparative studies from Magos et al and Sahin, however, demonstrated that uteri up to 20 weeks in size can be safely removed vaginally using specific surgical techniques such as bisection and intra-myometrial coring. ${ }^{23,24}$ Additionally, pre-operative medical debulking with gonadotrophic releasing hormone $(\mathrm{GnRH})$ analogues can increase the feasibility of $\mathrm{VH} .^{25,26}$ The aim of present study was to compare surgical outcomes and the safety of VH in women with nonprolapsed uteri of $>12$ weeks' size to those with uteri $<12$ weeks removed vaginally for similar indications. The comparison included - intra and post-operative complications, operating time, Intra and post-operative blood loss, post-operative pain, post-operative wound infection, post- operative recovery and Hospital stay

\section{METHODS}

This prospective study was conducted in department of Obstetrics and Gynaecology. 92 patients requiring hysterectomies for benign uterine conditions up to 18 weeks admitted to the Gynaecology ward between May 2016 to December 2018 fulfilling all inclusion and exclusion criteria were included.

\section{Inclusion criteria}

- Patients having benign uterine conditions (diagnosed by D and C, Pap smear, biopsy and USG) with nondescended uterus admitted for hysterectomy, who gave consent for the study, mobile uterus, prior 1 LSCS with above conditions.

\section{Exclusion criteria}

- $\quad$ Patients with complex adnexal mass.

\section{Methodology}

Patients admitted for hysterectomy were evaluated after written informed consent. Detailed history (including menstrual history, obstetrical history, past and family history) was taken. Complete physical as well as pelvic examination were done. Routine blood and systemic investigations were done. All patients were given prophylactic Inj. ceftriaxone on operation table just before skin incision. All the procedures were done by single surgeon. Time of surgery was measured from the start of incision to end of the procedure. To measure intraoperative blood loss, weight of swab in the dry and blood-soaked states was measured and $19 \mathrm{mg}$ weight difference was equated to $1 \mathrm{ml}$ blood loss. Temperature was assessed and charted 4 hourly, defining Febrile Morbidity as $38^{\circ} \mathrm{C}$ on 2 occasions 4 hours apart, excluding the first postoperative day. Patients were routinely receiving injectable analgesics on day 1 twice. After this, patients were given oral/injectable analgesics on request only and the total number of days of analgesic requirement were noted. Post-operative pain was measured according to visual analogue scale. Intraoperative blood loss and injuries, blood transfusion, post-operative mobility, febrile morbidity, infections, hospital stay were recorded.

\section{Operative technique}

All cases were operated under spinal anaesthesia. VH was performed using standard technique. In all cases per vaginal examination was done under anaesthesia before starting the surgery to have an idea about size, mobility of uterus and any adnexal mass. With aseptic measures the patients were cleaned and draped. The anterior lip of cervix was held with vulsellum and posterior lip with long Allie's forceps. Circular incision was made around the cervix, pubo-vesico-cervical ligament was cut and bladder mobilized upwards. At the site of previous scar bladder was sharply dissected out and then carefully mobilized upwards by speculum, till the anterior peritoneum covering the uterus is visible as glistening white. In cases of difficulty in separating the bladder the lateral window technique was done. The anterior peritoneum is opened carefully by applying two artery forceps and cutting in between. Posterior pouch was opened subsequently. Uterosacral and cardinal ligaments were clamped, cut and coagulated with bipolar clamp. Bilateral clamping of uterine vessels was done. After clamping and ligating uterine arteries on both sides, if the size of uterus was big then debulking techniques like bisection, coring, myomectomy or a combination of these methods were done to facilitate vaginal delivery of uterus. After delivering the uterus, hysterectomy was completed by applying bilateral cornual clamps, cutting and coagulating with bipolar clamp properly. All the pedicles were rechecked for any bleeding or oozing and vault is closed meticulously. ${ }^{12}$

\section{Statistical analysis}

Data were maintained on Microsoft Excel sheet. Data were expressed as percentages $(\%)$, Mean $\pm \mathrm{SD}$, or median and $25 \%$ to $75 \%$ inter-quartile range (IQR), as 
appropriate. Differences in baseline characteristics between patients undergoing NDVH with uterine size $<12$ weeks compare to $>12$ weeks had been done using student-t test for continuous variables with normal distribution and for non-normally distributed, MannWhitney U-test would be used. Categorical variables were compared by means of chi-square test (or Fisher's exact tests). P-values of $<0.05$ was defined as statistically significant.

\section{RESULTS}

Mean age of study subjects in index group was $44.00 \pm 5.243$ years while that of women in control group was $42.77 \pm 4.489$ years ( $p$ value 0.302 ). Most common presenting complaints were pain, excessive bleeding PV and white discharge in both the groups. Most of the women in both the groups had parity 3 or 4 with mean parity of 3.26 for index group and 3.78 for control group $(\mathrm{P}>0.05)$. The mean Haemoglobin of subjects in index group was $11.52(\mathrm{gm} / \mathrm{dl})$ while that of women in control group was $11.24(\mathrm{gm} / \mathrm{dl}) \quad(\mathrm{P}=0.9144)$. Most common medical comorbidities were Diabetes mellitus, Hypertension and thyroid disorders and most common surgical comorbidities were LAP sterilization, Abdominal sterilization and previous C-section in both the groups and difference in medical and surgical comorbidities were not significant in both the groups (Table 1).

Table 1: Demographic data.

\begin{tabular}{|l|l|l|l|l|}
\hline Baseline characteristic & Index group & Control group & P value & Significance \\
\hline Mean age (years) & $44.00 \pm 5.243$ & $42.77 \pm 4.489$ & 0.3026 & Not significant \\
\hline Parity & $3.263 \pm 1.076$ & $3.783 \pm 1.427$ & 0.7198 & Not significant \\
\hline BMI $\left(\mathrm{kg} / \mathrm{m}^{2}\right)$ & $20.83 \pm 1.332$ & $21.56 \pm 1.887$ & 0.7821 & Not significant \\
\hline $\begin{array}{l}\text { Mean Hemoglobin }(\mathrm{g} / \mathrm{dl}) \\
\text { Medical comorbidities }\end{array}$ & $11.24 \pm 1.161$ & $11.52 \pm 1.187$ & 0.9144 & Not significant \\
\hline Diabetes & $3(9.37 \%)$ & & \multirow{2}{*}{0.9271} & Not significant \\
\hline $\begin{array}{l}\text { Hypertension } \\
\text { Hypothyroidism }\end{array}$ & $6(18.75 \%)$ & $5(8.33 \%)$ & & \\
\hline Surgical comorbidities & $3(9.37 \%)$ & $4(11.66 \%)$ & & \\
\hline $\begin{array}{l}\text { Lap. sterilization } \\
\text { Abdominal sterilization }\end{array}$ & $10(31.25 \%)$ & $18(30 \%)$ & & \multirow{2}{*}{ Not significant } \\
\hline Previous C-section & $3(9.37 \%)$ & $8(13.33 \%)$ & & \\
\hline
\end{tabular}

The most common indication of hysterectomy in both the groups were Fibroid uterus followed by adenomyosis, chronic cervicitis, PID and endometrial hyperplasia in control group and adenomyomatosis in index group (Table 2).

Table 2: Indications of hysterectomy (Some patients had more than 1 indications).

\begin{tabular}{|l|l|l|}
\hline Indication of hysterectomy & $\begin{array}{l}\text { Index } \\
\text { group }\end{array}$ & $\begin{array}{l}\text { Control } \\
\text { group }\end{array}$ \\
\hline Fibroid & 22 & 26 \\
\hline Polyp & 3 & 5 \\
\hline Endometrial hyperplasia & 1 & 9 \\
\hline Adenomyosis & 7 & 14 \\
\hline PID & 2 & 9 \\
\hline Chronic cervicitis & 1 & 4 \\
\hline
\end{tabular}

The mean operative time of subjects in index group was $62.47 \pm 5.622 \mathrm{~min}$ while that of women in control group was $48.17 \pm 6.405 \mathrm{~min}$. This difference in mean Operative Time of subjects in both groups was found to be statistically significant $(\mathrm{P}<0.0001$. The mean Blood loss of subjects in index group was $123.2 \pm 15.47(\mathrm{ml})$ while that of women in control group was $75.90 \pm 12.45 \mathrm{ml}$ $(\mathrm{P}<0.0001)$. None of the Women in both the groups had any Intra op Complications. The mean Pain score of subjects in index group was $3.063 \pm 1.045$ while that of women in control group it was $3.033 \pm 1.377$. This difference in pain score in both the groups was not found to be statistically significant $(\mathrm{P}>0.05)$. The mean Hemoglobin drop in control group was $0.6800 \pm 0.1998$ $\mathrm{g} / \mathrm{dl}$, while in index group it was $1.0230 \pm 0.3115 \mathrm{~g} / \mathrm{dl}$. This difference in Hemoglobin drop in both groups was not found to be statistically significant $(\mathrm{P}=0.6265)$ and difference in number of units transfused was also not found to be statistically significant $(p=1.000)$. The mean Ambulation time of subjects in index group was $39.34 \pm 4.247$ hours while that of women in control group was $37.52 \pm 6.091$ hours $(\mathrm{P}>0.05)$. In both the groups most common complications seen were fever and systemic infection ( $p>0.05$ ). Pelvic hematoma developed in $3.1 \%$ in index group and $3.33 \%$ in control group ( $>>0.05)$. The mean Duration of hospital stay of subjects in index group was $5.531 \pm 1.391$ days while that of women in control group was $5.177 \pm 1.195$ days. This difference in mean duration of hospital stay of subjects in both group was not found to be statistically significant $(\mathrm{P}>0.05)$ (Table 3$)$. 
Table 3: Operative outcomes.

\begin{tabular}{|l|l|l|l|l|}
\hline Factor & Index group & Control group & p value & Statistical signifficance \\
\hline Operation duration (Min.) & $62.47 \pm 5.622$ & $48.17 \pm 6.405$ & $<0.0001$ & Significant \\
\hline Blood loss (ml) & $123.2 \pm 15.47$ & $75.90 \pm 12.45$ & $<0.0001$ & Significant \\
\hline Operative complications & None & None & & \\
\hline Post op pain (Visual analogue score) & $3.063 \pm 1.045$ & $3.033 \pm 1.377$ & 0.9169 & Not significant \\
\hline Hospital stay (Days) & $5.531 \pm 1.391$ & $5.177 \pm 1.195$ & 0.1380 & Not significant \\
\hline Post op ambulation (hours) & $39.34 \pm 4.247$ & $37.52 \pm 6.091$ & 0.7829 & Not significant \\
\hline Post op Hb drop (gm/dl) & $1.023 \pm 0.3115$ & $0.6800 \pm 0.1998$ & 0.6265 & Not significant \\
\hline Post op systemic infections & $2(6.25 \%)$ & $3(5 \%)$ & 0.695 & Not significant \\
\hline Post op fever & $3(9.37 \%)$ & $5(8.33 \%)$ & 0.784 & Not significant \\
\hline Pelvic hematoma & $1(3.1 \%)$ & $2(3.33 \%)$ & 0.816 & Not significant \\
\hline
\end{tabular}

\section{DISCUSSION}

Hysterectomy is common surgical procedure done by gynaecologists. Hysterectomy for benign uterine conditions can be done by Abdominal, Vaginal and Laparoscopic routes.

Each route has own merits and demerits. Lack of training could be the reason behind gynecologists' reluctance to perform VH especially in large sized uteri.

Studies from Magos et al and Sahin demonstrated that uteri up to 20 weeks in size can be safely removed vaginally using specific surgical techniques such as bisection and intra-myometrial coring. ${ }^{23,24}$

Not much literature present regarding safety of NDVH in large uterine size and hence this study was planned. This study was done to asses safety of $\mathrm{VH}$ for benign uterine conditions with large uterine size (>12 weeks) by comparing operative time, complications, post op recovery, intra operative blood loss and hospital stay with uterine size $<12$ weeks.

In present study, results suggest that $\mathrm{VH}$ for uteri $>12$ weeks in size, while taking longer to perform and having more blood loss, is safe, with post-operative complication rates and lengths of hospital stay that were not significantly different from VH for smaller uteri.

Similar results were observed in previous studies. ${ }^{27}$ More operative time was because of surgical debulking using various methods like bisection (Figure 1, 2 and 3), coring, myomectomy (Figure 4), (Figure 5) morcellation (Figure 6) or a combination of these methods. ${ }^{23,24,27}$

Mean blood loss in present study was significantly more in index group compared to control group and can be explained by more surface area of pathological mucosa and more need of surgical manipulation in this group of patients. This observation was similar to previous studies. $^{24,27}$
However, mean hemoglobin drop and need of blood transfusion in post-operative period for index group patients was not significantly different than control group.

In present study pain score on visual analogue scale was comparable for both the groups and this observation is supported by previous studies. ${ }^{27}$

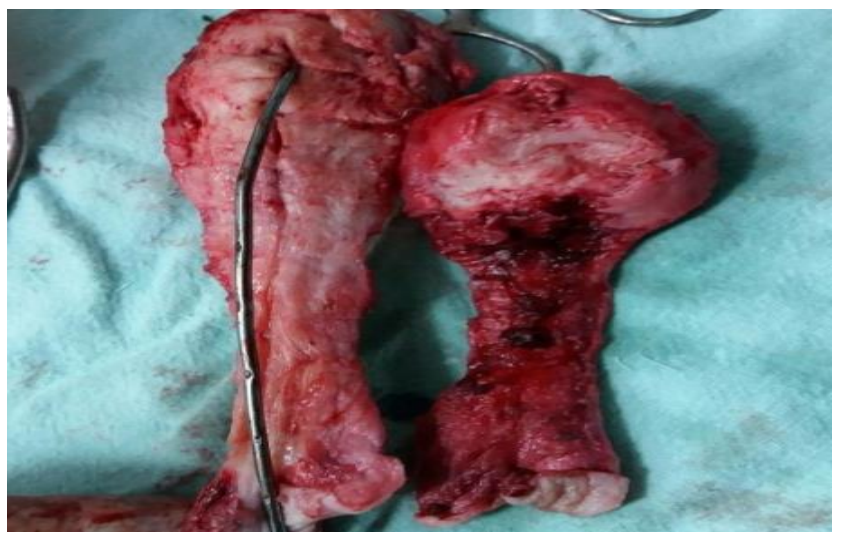

Figure 1: Uterine size 18 weeks removed after dissection.

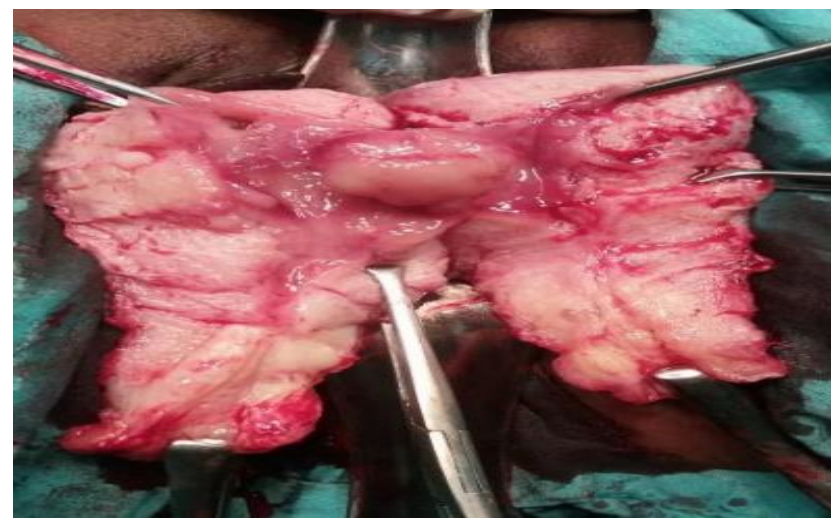

Figure 2: Uterine fibroid (12 weeks uterus) after dissection. 


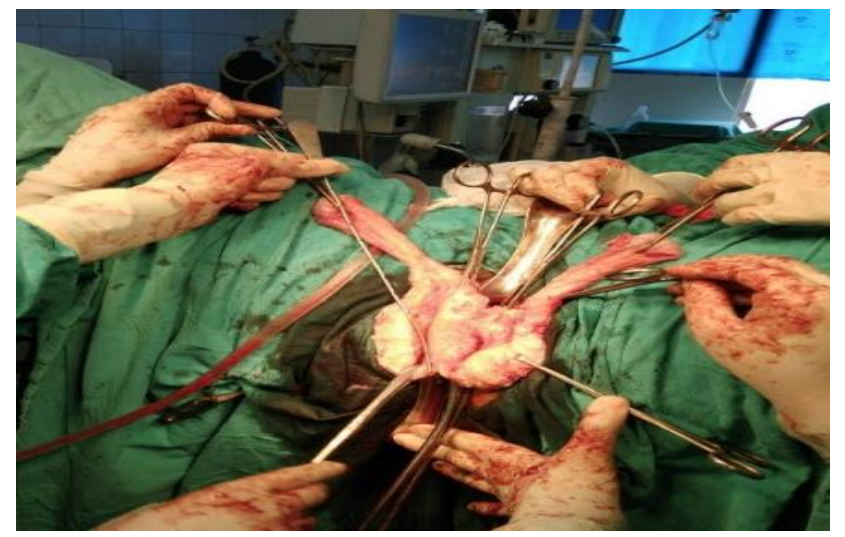

Figure 3: Bisection of uterus 18-week size.

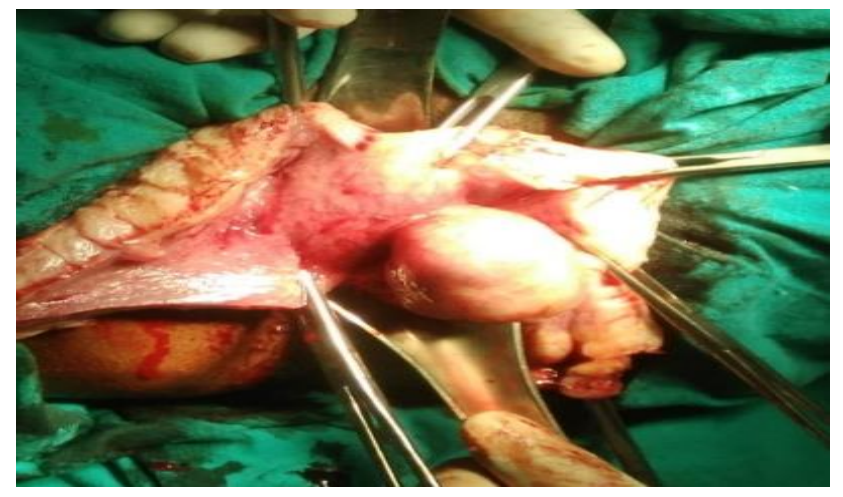

Figure 4: Myomectomy in 14 weeks size uterus

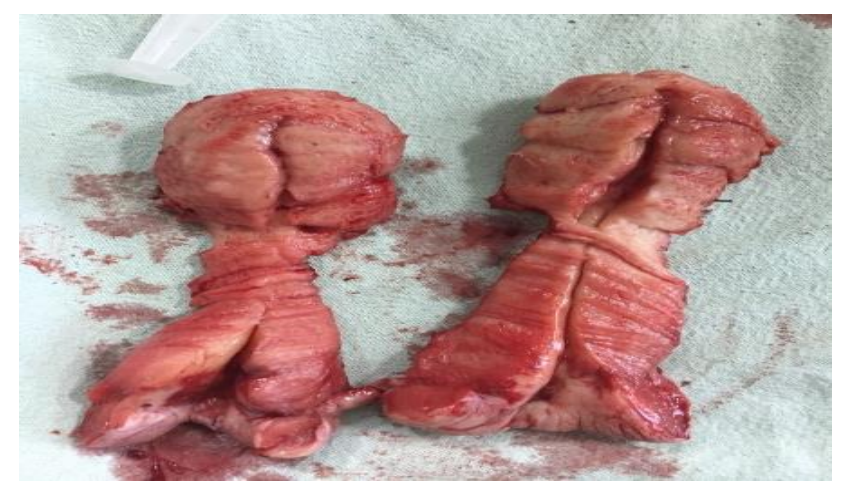

Figure 5: 16 weeks uterus with elongated cervix.

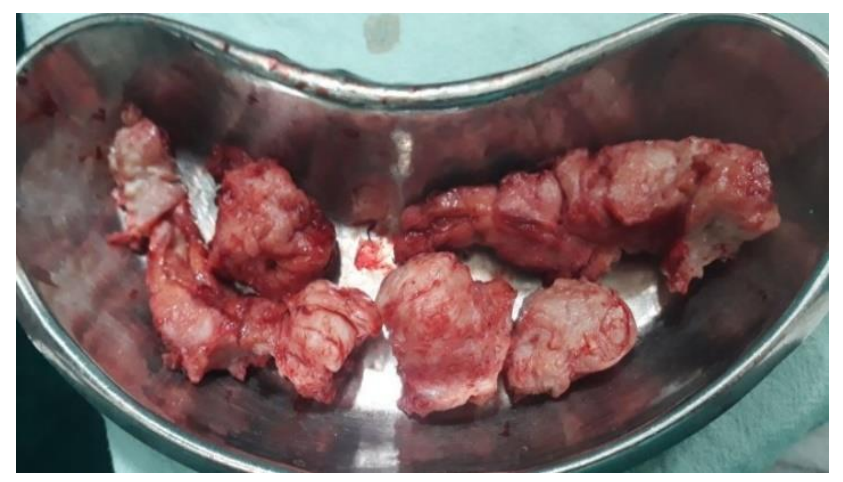

Figure 6: Fibroid morcellation in uterus of 14-16 weeks.
In present study, no intraoperative complication was noted in both the groups and no patients in both the group required conversion to abdominal hysterectomy. Most common post-operative complications in both the groups were febrile illness and systemic infections mainly UTI and Pneumonia. Pelvic hematomas were not significantly different in both the groups. In present study, mean ambulation time and mean duration of hospital stay were comparable in both the groups. Present study had several limitations; First it was a single centre study at tertiary hospital and could not be correlated with general population. Second, only surgical methods of debulking were used, medical method of debulking (GnRH analogue) was not used in both the groups of patients. Present study showed that compared to control group, index group had more operative time and intra operative blood loss, but post-operative pain, requirement of analgesics, mean ambulation time, hospital stay, and post-operative complications were comparable.

\section{CONCLUSION}

Hysterectomy by Non-descended vaginal route in patients with benign uterine conditions of $>12$ weeks found to be safe and could be considered in this group of patients.

\section{Funding: No funding sources}

Conflict of interest: None declared

Ethical approval: The study was approved by the Institutional Ethics Committee

\section{REFERENCES}

1. Vessey MP, Villard-Mackintosh LA, Mcpherson K, Coulter A, Yeates D. The epidemiology of hysterectomy: findings in a large cohort study. BJOG: Int J Obstet Gynaecol. 1992;99(5):402-7.

2. Niebuhr TE, Johnson N, Lethaby A, Tavender E, Curr E, Garry R, et al. Surgical approach to hysterectomy for benign gynaecological disease. Cochrane Database Syst Rev. 2009;(3):CD003677.

3. David-Montefiore E, Rouzier R, Chapron C, Darai E, Collegiale d'Obstétrique et Gynécologie de Paris-Ile de France. Surgical routes and complications of hysterectomy for benign disorders: a prospective observational study in French university hospitals. Human Reproduct. 2007;22(1):260-5.

4. Nieboer TE, Johnson N, Lethaby A, Tavender E, Curr E, Garry R et al. Surgical approach to hysterectomy for benign gynaecological disease. Cochrane Database of Systematic Reviews. 2009(3).

5. Aarts JW, Nieboer TE, Johnson N, Tavender E, Garry R, Mol BW, Kluivers KB. Surgical approach to hysterectomy for benign gynaecological disease. Cochrane Database of Systematic Reviews. 2015(8).

6. Ottosen C, Lingman G, Ottosen L. Three methods for hysterectomy: a randomised, prospective study of short-term outcome. BJOG. 2000;107(11):1380-5.

7. Ribeiro SC, Ribeiro RM, Santos NC, Pinotti JA. A randomized study of total abdominal, vaginal and 
laparoscopic hysterectomy. Int J Gynaecol Obstet. 2003;83(1):37-43.

8. American College of Obstetricians and Gynecologists. ACOG Committee Opinion. Number 311, April 2005. Appropriate use of laparoscopically assisted vaginal hysterectomy. Obstet Gynecol. 2005;105(4):929.

9. Yi YX, Zhang W, Zhou Q, Guo WR, Su Y. Laparoscopic-assisted vaginal hysterectomy vs abdominal hysterectomy for benign disease: a metaanalysis of randomized controlled trials. Europe J Obstet Gynecol Reproduct Biol. 2011 Nov $1 ; 159(1): 1-8$.

10. Coulam CB, Pratt JH. Vaginal hysterectomy: is previous pelvic operation a contraindication? Am J Obstet Gynecol. 1973;116(2):252-60.

11. Pitkin RM. Vaginal hysterectomy in obese women. Obstet Gynecol. 1977;49:567.

12. Pratt JH, Daikoku NH. Obesity and vaginal hysterectomy. J Reprod Med. 1990;35:945.

13. Akyol D, Esinler I, Guven S, Salman MC, Ayhan A. Vaginal hysterectomy: results and complications of 886 patients. J Obstet Gynaecol.2006;26(8):777-781.

14. Kennedy JS, Stranahan PL, Taylor KD, Chandler JG. High-burst strength, feedback-controlled bipolar vessel sealing. Surg Endosc. 1998;12(6):876-8.

15. Hefni MA, Bhaumik J, El-Toukhy T, Kho P, Wong I, Abdel- Razik T, et al. Safety and efficacy of using the LigaSure ${ }^{\mathrm{TM}}$ vessel sealing system for securing the pedicles in vaginal hysterectomy: randomised controlled trial. BJOG. 2005;112(3):329-33.

16. Cronjé HS, De Coning EC. Electrosurgical bipolar vessel sealing during vaginal hysterectomy. Int $\mathbf{J}$ Gynaecol Obstet. 2005;91(3):243- 5.

17. Elhao M, Abdallah K, Serag I, El-Laithy M, Agur W. Efficacy of using electrosurgical bipolar vessel sealing during vaginal hysterectomy in patients with different degrees of operative difficulty: a randomised controlled trial. Eur J Obstet Gynecol Reprod Biol. 2009;147(1):86-90.

18. Agrawal VB, Agrawal A, Agrawal SB. Comparison of efficacy of bipolar electrosurgical vessel sealing with conventional suturing in securing vascular pedicles during vaginal hysterectomy. Int J Med Sci Public Health. 2014;3(11):1325-9.
19. Levy B, Emery L. Randomized trial of suture versus electrosurgical bipolar vessel sealing in vaginal hysterectomy. Obstet Gynecol. 2003;102(1):147-51.

20. Silva-Filho AL, Rodrigues AM, Vale de Castro Monteiro M, da Rosa DG, Pereira e Silva YM, Werneck RA, et al. Randomized study of bipolar vessel sealing system versus conventional suture Ligasure for vaginal hysterectomy. Eur J Obstet Gynecol Reprod Biol 2009;146(2):200-3.

21. Benassi L, Rossi T, Kaihura CT, Ricci L, Bedocchi L, Galanti B, et al. Abdominal or vaginal hysterectomy for enlarged uteri: a randomized clinical trial. Am J Obstet Gynecol. 2002;187(6):1561-5.

22. Sushil K, Antony ZK. Vaginal hysterectomy for benign non-prolapsed uterus. Initial Experience. J Obstet Gynaecol Ind. 2004;54(1):60-63

23. Magos A, Bournas N, Sinha R, Richardson RE, O'Connor H. Vaginal hysterectomy for the large uterus. BJOG 1996;103(3):246-51.

24. Sahin Y. Vaginal hysterectomy and oophorectomy in women with 12-20 weeks' size uterus. Acta obstetricia et gynecologica Scandinavica. 2007;86(11):1359-69.

25. Stovall TG, Summit Jr RL, Washburn SA, Ling FW. Gonadotropin-releasing hormone agonist use before hysterectomy. Am J Obstet and Gynecol. 1994;170(5):1744-51.

26. Melendez J, Bhatia R, Fakokunde A, Yoong W. Medical debulking with gonadotrophin-releasing hormone agonists to facilitate vaginal hysterectomy. Gynecol Surg. 2012;9(1):77-80.

27. Newbold P, Vithayathil M, Fatania K, Yoong W. Is vaginal hysterectomy is equally safe for the enlarged and normally sized non-prolapse uterus? A cohort study assessing outcomes. Europe J Obstet Gynecol Reproduct Biol. 2015;185:74-7.

Cite this article as: Manda N, Nagar O, Rajoria L, Dadhich CP. Study on safety of non-descent vaginal hysterectomy for enlarged uterine size for benign uterine pathologies. Int J Reprod Contracept Obstet Gynecol 2019;8:1588-93. 